\title{
eJRIEPS
}

Ejournal de la recherche sur l'intervention en éducation physique et sport

$20 \mid 2010$

Varia

\section{Troisième Journée Alain Durey}

Jean-François Robin et Yannick Lemonie

Édition électronique
URL : http://journals.openedition.org/ejrieps/4777

DOI : 10.4000/ejrieps.4777

ISSN : 2105-0821

Éditeur

ELLIADD

\section{Référence électronique}

Jean-François Robin et Yannick Lemonie, «Troisième Journée Alain Durey », eJRIEPS [En ligne], 20

2010, mis en ligne le 01 avril 2010, consulté le 24 septembre 2020. URL : http://

journals.openedition.org/ejrieps/4777 ; DOI : https://doi.org/10.4000/ejrieps.4777

Ce document a été généré automatiquement le 24 septembre 2020.

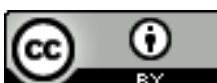

La revue eJRIEPS est mise à disposition selon les termes de la Creative Commons Attribution 4.0 International License. 


\section{Troisième Journée Alain Durey}

Jean-François Robin et Yannick Lemonie 
Pour finir, ce vingtième numéro de la revue eJRIEPS est la deuxième publication qui

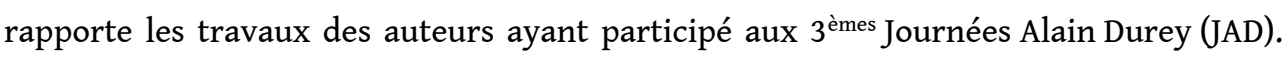
Régulièrement organisées à Paris en novembre, ces journées participent à la veille à propos de l'actualité des recherches en didactique de l'EPS, en didactique des APSA, et de technologique des APSA.

Ces troisièmes JAD s'inscrivent dans la continuité des rendez-vous annuels de l'INRP, puis plus récemment du GéDIAPS de l'Université de Créteil. C'est donc tout un patrimoine qui est apporté à cette occasion aux participants de ces journées de travail et de réflexion. Il nous semble important d'en conserver les traces dans une revue qui est également soucieuse de porter cet héritage. Cenuméro se veut utile à la construction d'une mémoire collective.

Ces troisièmes JAD veulent aussi mettre l'accent sur l'actualité des recherches dans ce champ. C'est pourquoi nous nous engageons délibérément dans la présentation de travaux de thèse soutenus dans l'année ou susceptibles d'être présentés très prochainement. Il s'agit donc d'aller à la source des travaux les plus récents.

Cependant, nous sommes également soucieux de créer les conditions d'un débat plus conjoncturel. C'est la raison pour laquelle une des deux journées de travail est consacrée à la réflexion et aux recherches en technologies des APSA. Là encore les travaux les plus récents sont mis en exergue. Ils se veulent une contribution à la compréhension des savoirs technologiques et des activités sportives et artistiques à des fins d'intervention en éducation ou en entraînement. Ils interrogent les référentiels disponibles pour la pratique.

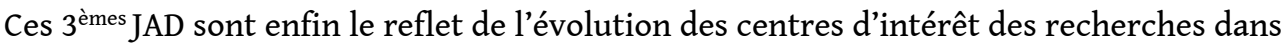
les domaines de la didactique et de la technologie. Ainsi, elles actent de paradigmes et de méthodologies novatrices.

Ce numéro spécial de la revue eJRIEPS a donc pour but de rendre compte des avancées significatives dans le champ des recherches en didactique de l'EPS, en didactique des APSA, et en technologie des APSA. Il suggère de débattre des résultats qui y sont présentés. Il invite enfin à participer aux initiatives automnales organisées sur le nouveau site du département STAPS de l'Université de Paris Est Créteil Val-de-Marne.

\section{AUTEURS}

\section{JEAN-FRANÇOIS ROBIN}

Éditeur scientifique invité du numéro 20.j

f.robin[@]u-pec.fr

\section{YANNICK LEMONIE}

Éditeur scientifique invité du numéro 20. yannick.lemonie[@]u-pec.fr 